\title{
BMJ Open Early socioeconomic position and self-rated health among civil servants in Brazil: a cross-sectional analysis from the Pró-Saúde cohort study
}

\author{
Joanna Miguez Nery Guimarães, ${ }^{1}$ Guilherme Loureiro Werneck, ${ }^{2}$ \\ Eduardo Faerstein, ${ }^{2}$ Claudia S Lopes, ${ }^{2}$ Dora Chor ${ }^{1}$
}

To cite: Guimarães JMN, Werneck GL, Faerstein $\mathrm{E}$, et al. Early socioeconomic position and self-rated health among civil servants in Brazil: a cross-sectional analysis from the Pró-Saúde cohort study. BMJ Open 2014:4:e005321.

doi:10.1136/bmjopen-2014005321

- Prepublication history for this paper is available online. To view these files please visit the journal online (http://dx.doi.org/10.1136/ bmjopen-2014-005321).

Received 25 March 2014 Revised 10 October 2014 Accepted 29 October 2014

\section{(a) CrossMark}

${ }^{1}$ Department of Epidemiology, National School of Public Health, Oswaldo Cruz Foundation, Rio de Janeiro, Brazil

${ }^{2}$ Department of Epidemiology, Institute of Social Medicine,

State University of Rio de Janeiro, Rio de Janeiro, Brazil

Correspondence to Joanna Miguez Nery Guimarães; joannaguimaraes@hotmail. com

\section{ABSTRACT}

Objectives: Although there is evidence that socioeconomic conditions in adulthood are associated with worse self-rated health, the putative effect of early adverse life circumstances on adult self-rated health is not consistent. Besides, little is known on this subject in the context of middle-income countries. We aimed to investigate the association between indicators of socioeconomic position in early life and self-rated health in adulthood, taking into account the influence of current socioeconomic position.

Design: Cross-sectional.

Participants: 3339 civil servants $(44.5 \%$ male) working at a public university in Rio de Janeiro, Brazil, participants of the Pró-Saúde cohort study.

Measurements: Through a lifecourse approach, we evaluated if seven indicators of participants' socioeconomic position earlier in life were associated with worse self-rated health in adulthood. Ordinal logistic regression analysis with a proportional odds model was used.

Results: After adjusting for socioeconomic position in adulthood (education and income), the indicators of early socioeconomic position associated with poor self-rated health were as follows: not eating at home due to lack of money at the age of $12(\mathrm{OR}=1.2995 \% \mathrm{Cl} 1.06$ to 1.57$)$ and having lived in a small city or rural area at the age of 12 (OR=1.51 95\% Cl 1.21 to 1.89 ).

Conclusions: Self-rated health was associated with two indicators of remarkable experiences of poverty in early life, even when socioeconomic conditions improved throughout life. Our findings have shown a long-term impact of extreme socioeconomic hardship during childhood and/or adolescence on the development of social inequalities in health. In terms of implications for public health, our work emphasises that health policies, usually focused on adult lifestyle interventions, should be complemented by initiatives aimed at reducing socioeconomic inequalities during the earliest stages of development, such as childhood and adolescence.

\section{INTRODUCTION}

Self-rated health (SRH) is an important health status indicator. It has been consistently found to be associated with socioeconomic and

\section{Strengths and limitations of this study}

- We found association between early socioeconomic position and adult self-rated health in Brazil, a middle-income country with a different socioeconomic and health profile, and a quite diverse historical and social trajectory, as compared to most developed countries where the reports on this issue come from.

- Utilisation of a wide set of socioeconomic position indicators of early life.

- An ordinal regression method enabled us to consider the ordinal relationship between the different strata of self-rated health.

- Selection bias is likely as a consequence of exclusion of participants with missing data for some of the study variables.

- The cross-sectional design excludes cohort members who had died prematurely, resulting in a potential bias.

demographic indicators, ${ }^{1}{ }^{2}$ use of health services, ${ }^{3}{ }^{4}$ morbidity ${ }^{5}{ }^{6}$ and mortality ${ }^{7-9}$ in various populations. Unlike objective health indicators (eg, medical diagnoses, laboratory examination results), SRH is a subjective measure that reflects an individual's perception of health, including its biological, psychological and social dimensions. ${ }^{10}$

Many epidemiological studies suggest a socioeconomic gradient related to SRH in which low educational attainment, ${ }^{1}{ }^{2}$ low income $^{11} 12$ and low-paying occupations ${ }^{13} 14$ are strongly associated with poor perceived health. In addition, some studies have shown that regardless of current socioeconomic conditions in adulthood, adverse socioeconomic circumstances in early stages of life are associated with worse SRH, ${ }^{5}{ }^{15-17}$ as well as greater risk of adult cardiovascular diseases ${ }^{18}$ and mortality. ${ }^{19}$ However, these findings are not consistent, since other studies demonstrate a null or attenuated effect of 
early life circumstances on SRH when adjusting for socioeconomic characteristics in adulthood. ${ }^{2021}$

Kuh et $a l^{22}$ propose the following mechanism to explain the relationship between socioeconomic circumstances in childhood and SRH in adulthood. Family circumstances (parental education level and income, and deprivation of essentials such as food) can limit access to opportunities for educational achievement, an important predictor of adult income and occupation, which in turn represents distal risk factors for health status in adulthood. In support of this view, there is evidence that individuals with favourable family backgrounds have a better chance of achieving a higher socioeconomic position (SEP) in adulthood. ${ }^{23}$ On the other hand, children born in families with a low SEP have fewer chances of finishing their studies. At the same time, the limited educational achievement of children from socially disadvantaged families is likely to limit their lifecourse opportunities and those of their offspring. ${ }^{24}$

Some studies show that socioeconomic disadvantage in childhood is associated with psychological and behavioural problems in childhood and adulthood, such as low perceived control and negative coping styles, that may contribute to poor health in adulthood, regardless of adult social class. ${ }^{1625}$ In addition, childhood and adolescence are critical periods for the development of health-related behaviours such as smoking, alcohol consumption, having an unhealthy diet and lack of exercise. $^{22}$ These behaviours-sedentary lifestyle in particular -partially explain the independent effect of childhood socioeconomic circumstances on adult health. ${ }^{15}$

The positive association between SEP in early life and SRH in adulthood has been investigated in high-income countries, ${ }^{5} 15202126$ but not in Latin-American populations. Studying this relationship among the Brazilian population is of particular interest, since Brazil went through a period of sharp sociodemographic transition during the second half of the 20th century and experienced important economic growth, which allowed an improvement in the living standards of the population.

Furthermore, most studies include only a few early SEP indicators ${ }^{15-1721}$ or analyse SRH as a dichotomous

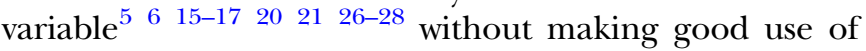
data collected using four or five answer options. Thus, the aim of this study was to investigate the role of several SEP indicators in early life on SRH in adulthood, taking into account the influence of characteristics of the individual's current SEP.

\section{METHODS}

\section{Study design and population}

The Pró-Saúde Study is a longitudinal prospective study of non-faculty civil servants at a university in Rio de Janeiro, Brazil, directed towards investigating social determinants of health outcomes. Cohort participants are mainly routine non-manual workers (eg, nurses, and administrative clerical and information technology staff), professional workers (eg, physicians and managers) and manual workers (eg, janitors, cooks, security personnel and other similar jobs). In the first stage of the study (1999), all permanent employees in technical administrative positions were considered eligible, except those who were on non-medical leave of absence or seconded to other institutions. From the 4448 eligible workers, the overall response rate was $90.6 \% \quad(n=4030)$. The cross-sectional analyses presented here included 3339 participants with valid data on all the questions under study.

\section{Measures}

The construct 'early SEP' (exposure) was represented by a set of seven questions on participants' socioeconomic and emotional experiences during childhood and adolescence: mother's and father's education level (high school or more/elementary/less than elementary), number of children of the biological mother $(1,2,3,4,5,6,7,8,9$, 10 or more), family's economic situation at the age of 12 (rich/average/poor/very poor), whether the participant stopped eating at home due to lack of money at the age of 12 (no/yes), type of area in which the participant lived at the age of 12 (capital or large city/small city or rural area) and age at which the participant started working $(\geq 18 /<18$ years). Multicollinearity among early SEP indicators was evaluated by calculating the variance inflation factor (VIF). The highest VIF was 1.70 (for mother's education level), which is well below the cut-off of 10.0 suggested by the literature. ${ }^{29}$

SRH (outcome) was measured by the following question: "In comparison with people of your age, how do you rate your own overall health status?" The answer options were 'very good', 'good', 'fair' or 'poor'. For the analyses, 'fair' and 'poor' were grouped into a single category, as only a small number of participants $(n=63)$ reported 'poor' SRH.

Adult SEP indicators (covariates) were education level (college or more/high school/elementary or less) and household per capita monthly income (analysed as a continuous variable and calculated as total family income divided by the number of dependents on that income). Other covariates were age (analysed as a continuous variable), gender and self-classified colour/race, on the basis of the Brazilian census ethnic categories: white, 'pardo' (mulatto), black and others (Asian and indigenous).

According to the proposed hierarchical theoretical model (figure 1), the relationship between early SEP and adult SRH may occur through a direct path (route I), in which adult SEP would act as a confounding variable, or through an indirect path (route II), in which adult SEP would act as a mediator. The confounding variablesgender, age and colour/race-are in the first level of the hierarchy; the exposure variables that represent early SEP are in the second level; and the confounding variables 
Figure 1 Hierarchical theoretical model for the relationship between socioeconomic position (SEP) earlier in life and self-rated health $(\mathrm{SRH})$ in adulthood. Pró-Saúde Study, 1999.

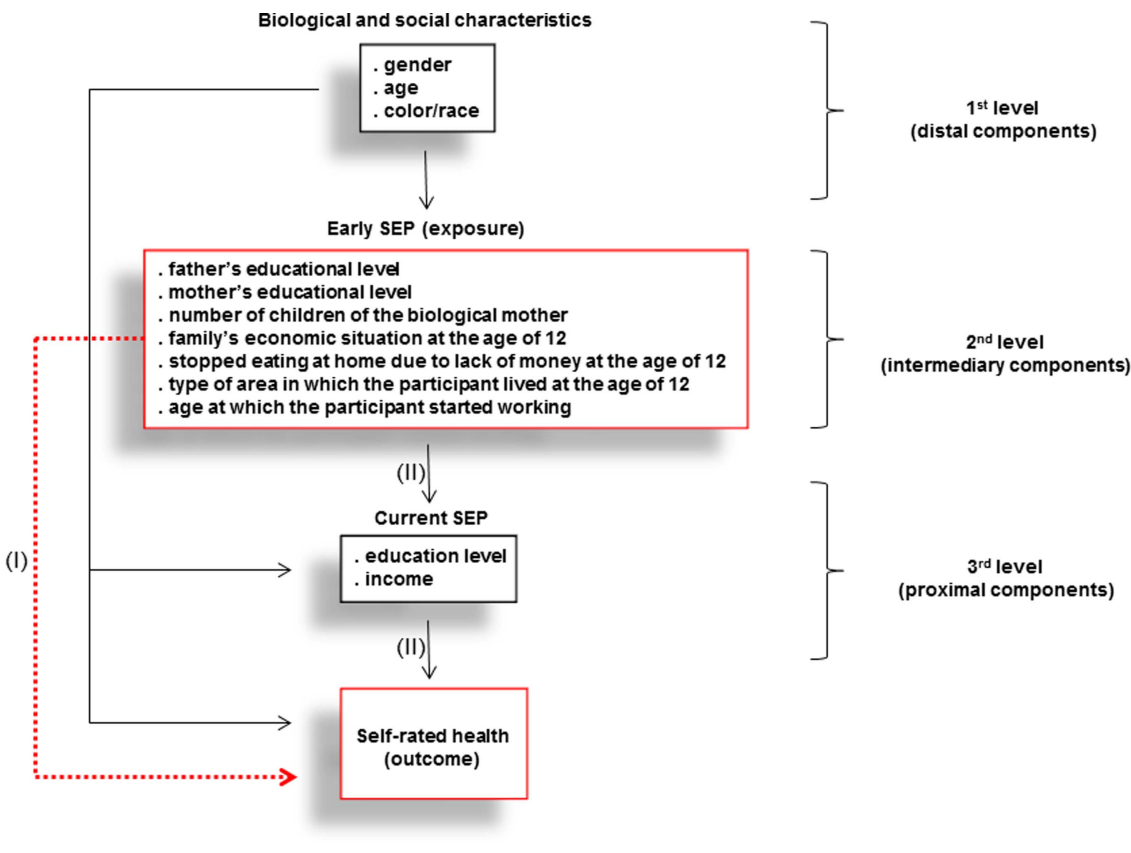

that represent adult SEP (education level and income) are in the third level.

\section{Statistical analysis}

The association between early SEP and adult SRH was evaluated through ordinal logistic regression analysis using a proportional odds model. The ordinal regression method has some analytical advantages: it maintains the inherent ordinality of the outcome's (SRH) answer options and estimates a single OR, which summarises the association, assuming that this is homogeneous for the different cut-points that separate the levels of the outcome variable. ${ }^{30}$

Initially, ordinal models adjusted for age, gender and colour/race were fitted and ORs of worst SRH were estimated ('fair or poor' vs 'good'+'very good'; 'fair or poor'+'good' vs 'very good') for each of the seven early SEP indicators (model 1). Variables of which the likelihood-ratio test was significant $(p<0.05)$ in model 1 were included in a full model from which they were removed one at a time through backward selection procedure. Starting with the variable with the highest $p$ value, non-significant $(\mathrm{p} \geq 0.05)$ variables were removed until a final model was obtained (model 2). Finally, in order to investigate the influence of adult SEP characteristics on the association between early SEP and adult SRH, education level and income were included in the final model, both separately (models 3 and 4) and simultaneously (model 5).

The assumption of proportionality of the odds was evaluated by the Brant test for the null hypothesis that there is no difference between the coefficients associated with the levels of the outcome variable. ${ }^{31}$ This assumption was violated for the variable "type of area at the age of 12". Thus, a generalised ordered logistic model was fitted, and two distinct ORs were estimated for each level of the outcome: (1) 'fair or poor' versus 'good'+'very good' and (2) 'fair or poor'+'good' versus 'very good.' All analyses were performed in Stata (version IC/11.1; Stata Corp, College Station, USA).

\section{RESULTS}

The group studied was mostly female (55.5\%) and predominantly young adults, with a mean age of 39.3 years (table 1). Over $50 \%$ classified themselves as white, and about $45 \%$ had completed undergraduate or postgraduate education. The average household per capita monthly income was US\$468. Early socioeconomic characteristics indicated low parental education level, particularly maternal education, and approximately $40 \%$ reported that their mothers had five or more children. At the age of 12, more than half of the participants rated their family's economic situation as 'poor' or 'very poor,' approximately $20 \%$ had lived in small cities or rural areas and $15 \%$ had had occasions when they could not eat at home due to lack of money. About $40 \%$ started working before the age of 18 .

Among the 3339 participants with complete data (83\% of the 4030 participants in stage 1), $28.7 \%$ rated their health as 'very good,' $54.9 \%$ as 'good,' $15 \%$ as 'fair' and $1.4 \%$ as 'poor'. Fair or poor SRH was more prevalent among women, participants who classified themselves as 'black,' those whose mothers had more children, those who had not eaten at home due to lack of money at age 12, those who lived in small cities or rural areas at age 12 and those who had started working before the age of $18(\mathrm{p}<0.001)$. The prevalence of fair or poor SRH gradually increased with age, with lowering levels of participant and parental education, and with worsening family economic situation at the age of 12 $(\mathrm{p}<0.001$, table 1$)$. 
Table 1 Sample characteristics and fair or poor self-rated health (SRH), according to the analysed variables

\begin{tabular}{|c|c|c|c|}
\hline Variables & $n^{*}(\%)$ & Fair or poor SRH-n (\%) & p Value \\
\hline \multicolumn{4}{|l|}{ SRH } \\
\hline Very good & $960(28.7)$ & - & - \\
\hline Good & 1832 (54.9) & - & - \\
\hline Fair or poor & 547 (16.4) & - & - \\
\hline \multicolumn{4}{|l|}{ Age } \\
\hline$<35(22-34)$ & $1035(31.0)$ & $113(10.9)$ & \multirow{4}{*}{$<0.001$} \\
\hline $35-44$ & 1455 (43.6) & $218(15.0)$ & \\
\hline $45-54$ & $668(20.0)$ & $154(23.0)$ & \\
\hline$>54$ (55-81 years) & $181(5.4)$ & $62(34.2)$ & \\
\hline \multicolumn{4}{|l|}{ Gender } \\
\hline Male & 1485 (44.5) & $198(13.3)$ & \multirow[t]{2}{*}{$<0.001$} \\
\hline Female & $1854(55.5)$ & 349 (18.8) & \\
\hline \multicolumn{4}{|l|}{ Colour/race } \\
\hline White & $1844(55.2)$ & $224(12.1)$ & \multirow[t]{4}{*}{$<0.001$} \\
\hline Pardo & $928(27.8)$ & $184(19.8)$ & \\
\hline Black & $487(14.6)$ & $123(25.3)$ & \\
\hline Others & $80(2.4)$ & $16(20.0)$ & \\
\hline \multicolumn{4}{|l|}{ Education level } \\
\hline College or more & $1488(44.6)$ & 147 (9.9) & \multirow[t]{3}{*}{$<0.001$} \\
\hline High school & $1220(36.5)$ & $202(16.6)$ & \\
\hline Elementary or less & 631 (18.9) & $198(31.4)$ & \\
\hline \multicolumn{4}{|l|}{ Mother's education level } \\
\hline High school or more & $804(24.1)$ & 88 (10.9) & \multirow[t]{3}{*}{$<0.001$} \\
\hline Elementary & $883(26.4)$ & $117(13.2)$ & \\
\hline Less than elementary & $1652(49.5)$ & $342(20.7)$ & \\
\hline \multicolumn{4}{|l|}{ Father's education level } \\
\hline High school or more & $1120(33.5)$ & $138(12.3)$ & \multirow[t]{3}{*}{$<0.001$} \\
\hline Elementary & $854(25.6)$ & $117(13.7)$ & \\
\hline Less than elementary & 1365 (40.9) & $292(21.4)$ & \\
\hline \multicolumn{4}{|c|}{ Number of children of the biological mother } \\
\hline 1 & $238(7.1)$ & $30(12.6)$ & \multirow[t]{6}{*}{$<0.001$} \\
\hline 2 & $659(19.7)$ & 70 (10.6) & \\
\hline 3 & $674(20.3)$ & $86(12.8)$ & \\
\hline 4 & $460(13.8)$ & $69(15.0)$ & \\
\hline $5-9$ & $971(29.1)$ & $193(19.9)$ & \\
\hline$\geq 10$ (10-23 children) & $337(10.1)$ & 99 (29.4) & \\
\hline \multicolumn{4}{|c|}{ Family's economic situation at the age of 12} \\
\hline Rich & $39(1.1)$ & $2(5.1)$ & \multirow[t]{4}{*}{$<0.001$} \\
\hline Average & 1595 (47.8) & $199(12.5)$ & \\
\hline Poor & $1469(44.0)$ & $279(19.0)$ & \\
\hline Very poor & $236(7.1)$ & $67(28.4)$ & \\
\hline \multicolumn{4}{|c|}{ Stopped eating at home due to lack of money at the age of 12} \\
\hline No & 2843 (85.2) & $426(15.0)$ & \multirow[t]{2}{*}{$<0.001$} \\
\hline Yes & $496(14.8)$ & $121(24.4)$ & \\
\hline \multicolumn{4}{|c|}{ Type of area in which the participant lived at the age of 12} \\
\hline Capital or large city & 2724 (81.6) & $385(14.1)$ & \multirow[t]{2}{*}{$<0.001$} \\
\hline Small city or rural area & $615(18.4)$ & $162(26.3)$ & \\
\hline \multicolumn{4}{|c|}{ Age at which the participant started working } \\
\hline$\geq 18(18-42)$ & $1984(59.4)$ & $264(13.3)$ & $<0.001$ \\
\hline$<18$ (4-17 years) & $1355(40.6)$ & $283(20.9)$ & \\
\hline
\end{tabular}

We found similar results across gender strata, then the analysis was performed adjusting for gender. The early SEP variables selected for adjustment in the multivariate ordinal analysis (table 2) were as follows: mother's education level, number of children of the biological mother, not having eaten at home due to lack of money at age 12 , age when participant started working and type of area in which the participant lived at the age of 12 (model 2). Thus, model 1 showed that an individual who had not eaten at home due to lack of money at the 
Table 2 ORs and Cls $(95 \% \mathrm{Cl})$ for the association between early socioeconomic position (SEP) and worse self-rated health in adulthood

\begin{tabular}{|c|c|c|c|c|c|}
\hline Early SEP & $\begin{array}{l}\text { Model } 1 \\
(\text { OR 95\% Cl) }\end{array}$ & $\begin{array}{l}\text { Model } 2 \\
(\text { OR 95\% Cl) }\end{array}$ & $\begin{array}{l}\text { Model } 3 \\
(\text { OR 95\% Cl) }\end{array}$ & $\begin{array}{l}\text { Model } 4 \\
\text { (OR 5\% Cl) }\end{array}$ & $\begin{array}{l}\text { Model } 5 \\
\text { (OR 5\% Cl) }\end{array}$ \\
\hline \multicolumn{6}{|l|}{ Mother's educational level } \\
\hline High school or more & 1.00 & 1.00 & 1.00 & 1.00 & 1.00 \\
\hline Elementary & 1.09 (0.91 to 1.32$)$ & $1.02(0.85$ to 1.23$)$ & $0.97(0.80$ to 1.17$)$ & $0.95(0.79$ to 1.15$)$ & $0.93(0.77$ to 1.13$)$ \\
\hline Less than elementary & $1.50(1.26$ to 1.78$)$ & 1.27 (1.06 to 1.52$)$ & $1.12(0.93$ to 1.35$)$ & $1.12(0.93$ to 1.35$)$ & 1.05 (0.87 to 1.27$)$ \\
\hline \multicolumn{6}{|l|}{ Father's educational level } \\
\hline High school or more & 1.00 & - & - & - & - \\
\hline Elementary & 0.99 (0.83 to 1.18$)$ & - & - & - & - \\
\hline Less than elementary & $1.31(1.11$ to 1.54$)$ & - & - & - & - \\
\hline Number of children of the biological mother & $1.07(1.04$ to 1.10$)$ & $1.04(1.01$ to 1.07$)$ & $1.01(0.99$ to 1.04$)$ & $1.02(0.99$ to 1.05$)$ & $1.01(0.98$ to 1.04$)$ \\
\hline \multicolumn{6}{|l|}{ Family's economic situation at the age of 12} \\
\hline Rich & 1.00 & - & - & - & - \\
\hline Average & $1.36(0.75$ to 2.49$)$ & - & - & - & - \\
\hline Poor & $2.02(1.10$ to 3.69$)$ & - & - & - & - \\
\hline Very poor & 2.47 (1.29 to 4.73$)$ & - & - & - & - \\
\hline \multicolumn{6}{|c|}{ Stopped eating at home due to lack of money at the age of 12} \\
\hline No & 1.00 & 1.00 & 1.00 & 1.00 & 1.00 \\
\hline Yes & $1.61(1.34$ to 1.95$)$ & $1.41(1.16$ to 1.71$)$ & $1.33(1.09$ to 1.61$)$ & 1.33 (1.09 to 1.62$)$ & 1.29 (1.06 to 1.57$)$ \\
\hline \multicolumn{6}{|l|}{ Age at which the participant started working } \\
\hline$\geq 18$ years & 1.00 & 1.00 & 1.00 & 1.00 & 1.00 \\
\hline$<18$ & $1.41(1.23$ to 1.63$)$ & $1.20(1.04$ to 1.40$)$ & $1.08(0.93$ to 1.25$)$ & $1.13(0.97$ to 1.31$)$ & 1.05 (0.90 to 1.22$)$ \\
\hline \multicolumn{6}{|l|}{ Early SEP (non-proportional variables) } \\
\hline & Fair or poor $\mathrm{x}$ & Fair or poor $\mathrm{x}$ & Fair or poor $\mathrm{x}$ & Fair or poor $\mathrm{x}$ & Fair or poor $\mathrm{x}$ \\
\hline Type of area in which the participant lived at the age of 12 & Good/very good & Good/very good & Good/very good & Good/very good & Good/very good \\
\hline Capital or large city & 1.00 & 1.00 & 1.00 & 1.00 & 1.00 \\
\hline \multirow[t]{4}{*}{ Small city or rural area } & $1.21(0.98$ to 1.49$)$ & $1.04(0.84$ to 1.28$)$ & $1.01(0.81$ to 1.25$)$ & $1.02(0.83$ to 1.27$)$ & $1.01(0.81$ to 1.25$)$ \\
\hline & $\begin{array}{l}\text { Fair or poor/good } \mathrm{x} \\
\text { very good }\end{array}$ & $\begin{array}{l}\text { Fair or poor/good } \mathrm{x} \\
\text { very good }\end{array}$ & $\begin{array}{l}\text { Fair or poor/good } \mathrm{x} \\
\text { very good }\end{array}$ & $\begin{array}{l}\text { Fair or poor/good } \mathrm{x} \\
\text { very good }\end{array}$ & $\begin{array}{l}\text { Fair or poor/good } \mathrm{x} \\
\text { very good }\end{array}$ \\
\hline & 1.00 & 1.00 & 1.00 & 1.00 & 1.00 \\
\hline & $1.79(1.44$ to 2.22$)$ & $1.55(1.24$ to 1.93$)$ & $1.51(1.21$ to 1.89$)$ & 1.54 (1.23 to 1.92$)$ & 1.51 (1.21 to 1.89$)$ \\
\hline
\end{tabular}

Pró-Saúde Study, 1999 ( $\mathrm{n}=3339)$.

Model 1: Each variable adjusted for age, gender and race; model 2: Final model with the selected early SEP variables, adjusted for age, gender and race; model 3: model 2, adjusted for education; model 4: model 2, adjusted for income; model 5: model 2, adjusted for education and income. 
age of 12 was 1.61 times as likely to report worse SRH than one who did not go through this situation $(95 \%$ CI 1.34 to 1.95 ), adjusting for age, gender and colour/race. After adjusting for age, gender, colour/race and selected early SEP indicators (model 2), this association was attenuated $(\mathrm{OR}=1.4195 \%$ CI 1.16 to 1.71$)$ but remained statistically significant, even after additional simultaneous adjustment for education level and income ( $\mathrm{OR}=1.29$ $95 \%$ CI 1.06 to 1.57 ; model 5 ).

Following the same steps of analysis, the early SEP indicator that had also shown an association with SRH, regardless of the other early SEP indicators and the adult SEP indicators (education level and income), was the type of area where the participant had lived at the age of 12. Participants who lived in small cities or rural areas were 1.51 times as likely (95\% CI 1.21 to 1.89 ) to report worse SRH than those who lived in the capital or in large cities.

\section{DISCUSSION}

Our study showed that adverse socioeconomic conditions in childhood, represented by two indicators ('stopped eating at home due to lack of money' and 'type of area in which the participant lived') among the seven investigated, were associated with worse SRH in adulthood. These associations were attenuated but remained significant even after adjusting for current socioeconomic characteristics (education and income). Our results are in agreement with studies showing that poverty in childhood and/or adolescence has negative effects on the perceived health status that persist until adulthood, even when socioeconomic conditions improve throughout life. ${ }^{5}{ }^{6} 15-17$ 26-28 32-34 On the other hand, some studies suggest that the association between early SEP and adult SRH is fully explained by adult socioeconomic status. ${ }^{20} 21$ However, the indicators used in different studies are quite diverse and, in general, few indicators are used. In addition, few studies adjust early SEP indicators for each other, as in our analysis, in order to identify the independent effect of each indicator, which would tend to reduce the magnitude of the association.

Our results demonstrated that those who stopped eating at home due to lack of money at the age of $12 \mathrm{had}$ a higher risk of assessing their health as worse, regardless of education level and income. Nicholson $e t a l^{3}$ found similar results, showing that individuals aged 15 years who often went to bed hungry had a higher risk of poor or very poor adult SRH, when adjusting for education and income. Food insecurity during childhood is considered a good marker of deprivation and vulnerability, and is associated with emotional and psychological stress in childhood. In this way, it could have a negative long-term effect on health and contribute to a higher risk of chronic disease. ${ }^{35}$

Our results also indicate that living in a rural area or small town (ie, city with up to 50 thousand inhabitants) at the age of 12 was associated with a higher risk of worse
SRH, even after adjusting for current characteristics (education and income). Similarly, Wen and $\mathrm{Gu}^{34}$ showed that elderly people born in urban areas had a $23 \%$ decrease in the odds of poor SRH, after adjusting for adult socioeconomic conditions. In contrast, Rahkonen $e t a l^{27}$ found that the increased risk of poor SRH among individuals who lived in rural areas during childhood was not significant in relation to those who lived in urban centres. Sucur and Zrinšcak ${ }^{36}$ observed that residents of rural areas are more likely to develop long-term diseases, usually live far from health services and assess their health as worse, compared to those who live in urban areas.

In Brazil, over 50 years ago, during the childhood and adolescence of the studied cohort, socioeconomic differences between rural areas and urban centres were markedly wider than today. Rural areas had fewer wellconstructed homes; poor access to appropriate services of education, health and transport; and lack of attention from public authorities. ${ }^{37}$ All these conditions have a negative effect on health and may also affect adult SRH.

Our results showed a cumulative effect of adverse socioeconomic circumstances during childhood and adulthood on SRH. This effect was observed for two of the investigated exposure variables (at the age of 12 , "stopped eating at home due to lack of money" and "type of area in which the participant lived"). For the remaining variables, the material conditions throughout life seemed to compensate for the socioeconomic adversities experienced in early life (eg, the association between mother's education and SRH lost statistical significance when adjusted for education and/or income). The family's economic situation at the age of 12-though an important indicator of household material resources and an independent risk factor for $\mathrm{SRH}^{5}{ }^{6}{ }^{26}{ }^{27}$-was no longer significantly associated with SRH when other early SEP indicators were included in the model. The wide set of early SEP indicators used in our study, along with an initial adjustment for colour/race (table 2, model 2), may partially explain the absence of this association.

Parents' education level is one of the most common indicators in the literature to represent socioeconomic conditions earlier in life, because it has a potential effect on all stages of children's lives. ${ }^{5} 2026-2832$ Unlike previous studies, ${ }^{5} 272832$ we found no independent association between parents' educational level and SRH. A cohort effect is a possible explanation for this difference. Our sample was mostly composed of people born in the $1950 \mathrm{~s}$ and $1960 \mathrm{~s}$, a generation whose parents often had difficulties in accessing formal education in Brazil, compared to other countries. Thus, this characteristic varied little among our participants (approximately $70 \%$ of parents had only completed elementary education), which can justify our results. Confirming this hypothesis, a study conducted in Spain by Regidor et $a l^{26}$ demonstrated that low paternal educational level increased the risk of poor SRH for younger women born between 1960 and 1980 but not for those born between 1941 and 1959, after adjusting for adult SEP. 
The strengths of this study are, first, the utilisation of a wide set of SEP indicators of early life, which allowed an in-depth investigation of the influence of different dimensions of early socioeconomic conditions on health outcomes during adulthood, thus leading to a more realistic conclusion. This strategy is supported by some authors ${ }^{38}$ who recommend the use of various socioeconomic indicators while studying health-related issues. Second, the analysis method used enabled us to investigate outcomes at different strata while considering the ordinal relationship between them. Lastly, regarding external validity, our cohort had high heterogeneity in terms of age, gender, educational level, income and colour/race, allowing for inferences that are potentially generalisable to the middle class of the economically active population in large Brazilian cities.

One of the limitations of this study is the fact that information concerning early SEP was obtained through retrospective reports, although empirical evidence demonstrates the accuracy of recall in the estimation of childhood SEP. ${ }^{39}{ }^{40}$ In addition, as an association was found between only two indicators, there is no indication that our results are biased. However, selection bias is still likely as a consequence of exclusion of participants with missing data for some of the study variables. Individuals with missing data $(17 \%)$ were older, had lower income and education levels and even worse early SEP than the studied sample. Thus, the non-participation of this group probably led to an underestimation of the effect estimates, since these characteristics are associated with a higher outcome risk (ie, worse SRH). Finally, the crosssectional design is not ideal for this analysis, as it excludes cohort members who had died prematurely, resulting in a potential bias towards the null.

In conclusion, our results showed that adverse SEP indicators during childhood increased the risk of worse SRH and that this effect was not entirely explained by socioeconomic characteristics during adulthood, supporting evidence from other studies. However, these findings are not consistent and require further research in various populations. Since there are indications that childhood health mediates the relationship between childhood SEP and adult $\mathrm{SRH},{ }^{32}$ future studies should examine the role of health during childhood in the relationship between early SEP and SRH in adulthood. In terms of implications for public health, our work emphasises that health policies, usually focused on adult lifestyle interventions, should be complemented by initiatives aimed at reducing poverty and socioeconomic inequalities during the earliest stages of development, such as childhood and adolescence. Cash transfer programmes, which transfer cash to poor families when they comply with conditions related to health and education of their children (eg, Brazil's Bolsa Familia programme), have shown a positive impact in this sense. ${ }^{41}$

Acknowledgements The authors thank the research assistants who participated in data collection and management.
Contributors JMNG wrote the first draft of the manuscript and carried out the data analyses. JMNG, DC and GLW were responsible for the conception, design and interpretation of the data. EF and CSL contributed to the interpretation of the data and revision of the manuscript. All authors provided references, commented on the draft of the paper and approved the final version.

Funding This work was supported by Carlos Chagas Filho Research Foundation of Rio de Janeiro-FAPERJ grants number E-26/102.398/2009 and E-26/111.294/2010.

Competing interests None.

Patient consent Obtained.

Ethics approval The research protocols were approved by the Ethics Committee of Rio de Janeiro State University.

Provenance and peer review Not commissioned; externally peer reviewed.

Data sharing statement No additional data are available.

Open Access This is an Open Access article distributed in accordance with the Creative Commons Attribution Non Commercial (CC BY-NC 4.0) license, which permits others to distribute, remix, adapt, build upon this work noncommercially, and license their derivative works on different terms, provided the original work is properly cited and the use is non-commercial. See: http:// creativecommons.org/licenses/by-nc/4.0/

\section{REFERENCES}

1. Szwarcwald CL, Souza-Júnior PR, Esteves MA, et al. Socio-demographic determinants of self-rated health in Brazil Cad Saude Publica 2005;21(Suppl):54-64.

2. Nedjat S, Hosseinpoor AR, Forouzanfar MH, et al. Decomposing socioeconomic inequality in self-rated health in Tehran. J Epidemiol Community Health 2012;66:495-500.

3. Miilunpalo S, Vuori I, Oja P, et al. Self-rated health status as a health measure: the predictive value of self-reported health status on the use of physician services and on mortality in the working-age population. J Clin Epidemiol 1997;50:517-28.

4. DeSalvo KB, Fan VS, McDonell MB, et al. Predicting mortality and healthcare utilization with a single question. Health Serv Res 2005;40:1234-46.

5. Moody-Ayers S, Lindquist K, Saunak S, et al. Childhood social and economic well-being and health in older age. Am J Epidemiol 2007;166:1059-67.

6. Chittleborough CR, Taylor AW, Baum FE, et al. Monitoring inequities in self-rated health over the life course in population surveillance systems. Am J Public Health 2009;99:680-9.

7. Idler EL, Benyamini Y. Self-rated health and mortality: a review of twenty-seven community studies. J Health Soc Behav 1997;38:21-37.

8. DeSalvo KB, Bloser N, Reynolds K, et al. Mortality prediction with a single general self-rated health question. A meta-analysis. J Gen Intern Med 2006;21:267-5.

9. Guimarães JMN, Chor D, Werneck GL, et al. Association between self-rated health and mortality: 10 years follow-up to the Pro-Saude cohort study. BMC Public Health 2012;12:676.

10. Jylhä $M$. What is self-rated health and why does it predict mortality? Towards a unified conceptual model. Soc Sci Med 2009;69:307-16.

11. Lim WY, Ma S, Heng D, et al. Gender, ethnicity, health behaviour \& self-rated health in Singapore. BMC Public Health 2007;7:184.

12. Ahnquist J, Wamala SP, Lindstrom M. Social determinants of health -a question of social or economic capital? Interaction effects of socioeconomic factors on health outcomes. Soc Sci Med 2012;74:930-9.

13. Chandola T, Ferrie J, Sacker A, et al. Social inequalities in self reported health in early old age: follow-up of prospective cohort study. BMJ 2007;334:990.

14. Fujishiro K, Xu J, Gong F. What does "occupation" represent as an indicator of socioeconomic status?: exploring occupational prestige and health. Soc Sci Med 2010;71:2100-7.

15. van de Mheen H, Stronks K, Looman CW, et al. Does childhood socioeconomic status influence adult health through behavioural factors? Int J Epidemiol 1998;27:431-7.

16. Bosma $H$, van de Mheen HD, Mackenbach JP. Social class in childhood and general health in adulthood: questionnaire study of contribution of psychological attributes. BMJ 1999;318:18-22.

17. Hyde $M$, Jakub $H$, Melchior $M$, et al. Comparison of the effects of low childhood socioeconomic position and low adulthood 
socioeconomic position on self-rated health in four European studies. J Epidemiol Community Health 2006;60:882-6.

18. Galobardes B, Smith GD, Lynch JW. Systematic review of the influence of childhood socioeconomic circumstances on risk for cardiovascular disease in adulthood. Ann Epidemiol 2006;16:91-104.

19. Smith GD, Hart C, Blane D, et al. Adverse socioeconomic conditions in childhood and cause specific adult mortality: prospective observational study. BMJ 1998;30:1631-5.

20. Osler M, Madsen M, Nybo Andersen AM, et al. Do childhood and adult socioeconomic circumstances influence health and physical function in middle-age? Soc Sci Med 2009;68:1425-31.

21. McKenzie SK, Carter KN, Blakely T, et al. Effects of childhood socioeconomic position on subjective health and health behaviours in adulthood: how much is mediated by adult socioeconomic position? BMC Public Health 2011;11:269.

22. Kuh D, Power C, Blane D, et al. Socioeconomic pathways between childhood and adult health. In: Kuh D, Ben-Shlomo Y, eds. A Life course approach to chronic disease epidemiology. Oxford University Press, 2004:371-95.

23. Corcoran M. Rags to rags: poverty and mobility in the United States. Annu Rev Sociol 1995;21:237-67.

24. Fergusson DM, Horwood LJ, Boden JM. The transmission of social inequality: examination of the linkages between family socioeconomic status in childhood and educational achievement in young adulthood. Res Soc Stratif Mobil 2008;26:277-95.

25. Lynch JW, Kaplan GA, Salonen JT. Why do poor people behave poorly? Variation in adult health behaviours and psychosocial characteristics by stages of the socioeconomic lifecourse. Soc Sci Med 1997;44:809-19.

26. Regidor E, Pascual C, Martínez D, et al. Heterogeneity in the association between socioeconomic position in early life and adult self-rated health in two birth cohorts of Spanish adults. J Epidemiol Community Health 2011;65:999-1005

27. Rahkonen O, Lahelma E, Huuka M. Past or present? Childhood living conditions and current socioeconomic status as determinants of adult health. Soc Sci Med 1997;44:327-36.

28. Kestilä L, Koskinen S, Martelin T, et al. Determinants of health in early adulthood: what is the role of parental education, childhood adversities and own education? Eur J Public Health 2006;16:306-15.
29. Kleinbaum DG, Kupper LL, Muller KE, et al. Applied regression analysis and other multivariable methods. Pacific grove: Duxbury Press, 1998.

30. Scott SC, Goldberg MS, Mayo NE. Statistical assessment of ordinal outcomes in comparative studies. J Clin Epidemiol 1997;50:45-55.

31. Long JS, Freese J. Regression models for categorical and limited dependent variables using Stata. College Station, Texas: Stata Press, 2006.

32. Luo Y, Waite LJ. The impact of childhood and adult SES on physical, mental, and cognitive well-being in later life. J Gerontol B Psychol Sci Soc Sci 2005;60:S93-101.

33. Nicholson A, Bobak M, Murphy M, et al. Socio-economic influences on self-rated health in Russian men and women-a life course approach. Soc Sci Med 2005;61:2345-54.

34. Wen M, Gu D. The effects of childhood, adult, and community socioeconomic conditions on health and mortality among older adults in China. Demography 2011;48:153-81.

35. Kirkpatrick SI, McIntyre L, Potestio ML. Child hunger and long-term adverse consequences for health. Arch Pediatr Adolesc Med 2010;164:754-62.

36. Šucur Z, Zrinšcak S. Differences that hurt: self-perceived health inequalities in Croatia and European Union. Croat Med J 2007;48:653-66.

37. Santos SM, Chor D, Werneck GL, et al. Association between contextual factors and self-rated health: a systematic review of multilevel studies. Cad Saude Publica 2007;23:2533-54.

38. Braveman PA, Cubbin C, Egerter S, et al. Socioeconomic status in health research: one size does not fit all. JAMA 2005;294:2879-88.

39. Krieger N, Okamoto A, Selby JV. Adult female twins' recall of childhood social class and father's education: a validation study for public health research. Am J Epidemiol 1998;147:704-8.

40. Haas SA. The long-term effects of poor childhood health: an assessment and application of retrospective reports. Demography 2007;44:113-5.

41. Rasella D, Aquino R, Santos CA, et al. Effect of a conditional cash transfer programme on childhood mortality: a nationwide analysis of Brazilian municipalities. Lancet 2013;382:57-64. 